Metascience (2011) 20:509-511

DOI 10.1007/s11016-011-9540-6

BOOK REVIEW

\title{
Remembering Kolmogorov
}

Harold H. McFadden (trans.): Kolmogorov in perspective.

Series: History of mathematics. Vol. 20. American Mathematical

Society/London Mathematical Society, 2000 (reprint 2006), $\mathrm{x}+230 \mathrm{pp}, \$ 51 \mathrm{~PB}$

\section{Paul M. B. Vitányi}

Published online: 6 April 2011

(C) Springer Science+Business Media B.V. 2011

This interesting volume contains a Preface, an extensive biographical sketch of Kolmogorov's life and works by the probabilist A. N. Shiryaev, four essays by former graduate students remembering Kolmogorov, a moving tribute to Kolmogorov by his lifelong friend, the topologist Paul Aleksandrov, a similar tribute by Kolmogorov to Aleksandrov, an essay by Kolmogorov about Newton, and an exhaustive bibliography of Kolmogorov's works. The translation from Russian into English by H.H. McFadden is excellent. There are many photographs.

I have read the book with fascination, even though some of its mathematical contents were beyond me. These are relatively few and do not need to distract the reader. I have no doubt that when extensive biographies of Kolmogorov will be written in the future, the biographers will glean many details from this collection.

Kolmogorov was a "Giant of Mathematics" in the words of his Obituary in The Times. In the twentieth century mathematics, he had few equals. He enriched nearly every part of mathematics, with the exception of number theory. There are many theorems, lemmas, and even an entire theory which bear his name: KAM (Kolmogorov-Arnol'd-Moser) theory. His little book "Foundations of Probability Theory" (1933) in which he defined probability theory as a branch of measure theory and formulated the so-called Kolmogorov Axioms shaped probability theory.

In 1935, Kolmogorov and Aleksandrov acquired (initially part of) an old manor house at Komarovka [the former Stanislavskii dacha], with room for a large library and several guests. As P. Halmos visiting Kolmogorov in Moscow in 1965 says: "Kolmogorov [had] five rooms [apartment in the University]... stacks of reprints in one corner, a collection of theatrical masks somewhere, and a couple of skis

P. M. B. Vitányi ( $\square)$

CWI, Science Park 123, 1098 XG Amsterdam, The Netherlands

e-mail: Paul.Vitanyi@cwi.nl

P. M. B. Vitányi

Computer Science, University of Amsterdam, Amsterdam, The Netherlands 
somewhere else. "Is this where you work?" I asked. "No, no", he said: "I work out at the dacha; I am here only 3 days a week" ". Shiryaev's Biographical Sketch treats extensively Kolmogorov's scientific work including his solution of Hilbert's 13th problem. In the 1960s, Kolmogorov formulated more precisely R. von Mises's approach to "Kollektivs". Together with his axiomatic work on probability theory, this is usually regarded as solving (or partially solving) Hilbert's sixth problem.

In the 1970s (not reported by Shiryaev), he formulated precisely the notion of Kolmogorov's structure function that abstractly formulates the problem of statistical inference, and, in an extension, rate distortion and lossy compression. He is the most highly decorated mathematician in the former Soviet Union. He died of Parkinson's disease when he was 83 .

In his original contribution, Arnol'd, one of Kolmogorov's students, reminisces about the human side of Kolmogorov and the way he worked. He comments on Kolmogorov's work on turbulence (the "Kolmogorov spectrum" and other such concepts are familiar to every physicist) and related matters, which, according to Kolmogorov, arose in 1953 with new hope. Recall that 1953 is the year Stalin died. Kolmogorov was never a member of the Communist Party. Significantly, Arnol'd speaks about "pressure exerted on him [Kolmogorov] by some evil genius whose influence was enormous... he hardly lived in times when it became possible to speak of these things... like all people of his generation who lived through the 1930s and 1940s he was afraid of "them" to his last day". His attention span for a mathematical problem was a self-proclaimed 2 weeks, and he thought that every single discovery should fit in a four-page Doklady note, since "the human brain is not capable of creating anything more complicated at one time". Interesting is the discussion about the different stages of a new problem/theory and Kolmogorov's view and work habits. The reminiscences add on an even more personal note with letters written by Kolmogorov. In a letter of March 28, 1965, he explains why at his age he is more interested in his own problems, which he understands, and deals less with new directions of the young, even though they may be objectively valuable.

The contribution by S. M. Nikol'skii surveys some of Kolmogorov's work on functions of a real variable and offers personal remembrances about Kolmogorov as an organizer (in academics). Here, we see the important result of a periodic function whose Fourier series diverges everywhere (1923).

In the contribution by Ya. G. Sinai, memories of Kolmogorov by one of his students (class of 1956) are recounted. This class included the author, but also A.N. Shiryaev. The author relates personal experiences with Kolmogorov, such as him saying "a most rational measure would be to allow contraceptives to be sold at the university". It also illustrates an aspect of Kolmogorov that comes back time and again in the remembrances by colleagues and students. He valued in other people very highly (often unjustifiably so) qualities that he thought he himself lacked. He also imagined his companion in a conversation to be much better than in fact he was. Sinai also thinks that Kolmogorov liked concrete experiments as a motivation to develop theories. For instance, in inventing his similarity laws in the theory of turbulence, he analyzed experimental results for over half a year.

P. L. Ul'yanov was not Kolmogorov's student or research assistant. But acquaintance with Kolmogorov influenced his life. He relates about being invited 
often to the dacha in Komarovka. It seemed that Aleksandrov, more so than Kolmogorov, took responsibility of running the household.

In P. S. Aleksandrov's contribution his friendship (over 50 years) with Kolmogorov is recollected. He discusses Kolmogorov's scientific accomplishments, as well as his many (first place among Soviet mathematicians) memberships of scientific academies, honorary doctorates, some details about his birth and upbringing, and a list of his many students and pupils (incomplete). In Kolmogorov's own Memories of P. S. Aleksandrov, Kolmogorov echoes the words in the above contribution of Aleksandrov: "for me these 53 years of close and indissoluble friendship were the reason why all my life was on the whole full of happiness, and the basis of that happiness was the unceasing thoughtfulness on the part of Aleksandrov". He says: "We got to know one another shortly after my arrival at Moscow University in 1920. Our first encounters in 1920-1929 are described in Chapter I. The whole of Chapter II is devoted to our travels in 1929 along the Volga and in the Caucasus. Chapter III tells of our travels abroad (to Goettingen and Paris) in 1930-1931. In conclusion there are extracts from Aleksandrov's letters to me from the USA, where he stayed for about 4 months after leaving Europe in the Spring of 1931". Some (non-scientific) details of Shiryaev's Biography come from here.

In Kolmogorov's Newton and Contemporary Mathematical Thought, he attempts "to study the methodology of the scientist in the first place directly from his scientific works, and not from his methodological pronouncements". Kolmogorov believes that in Newton's case the latter are not representative because of fear of "controversy" and "philosophy". 